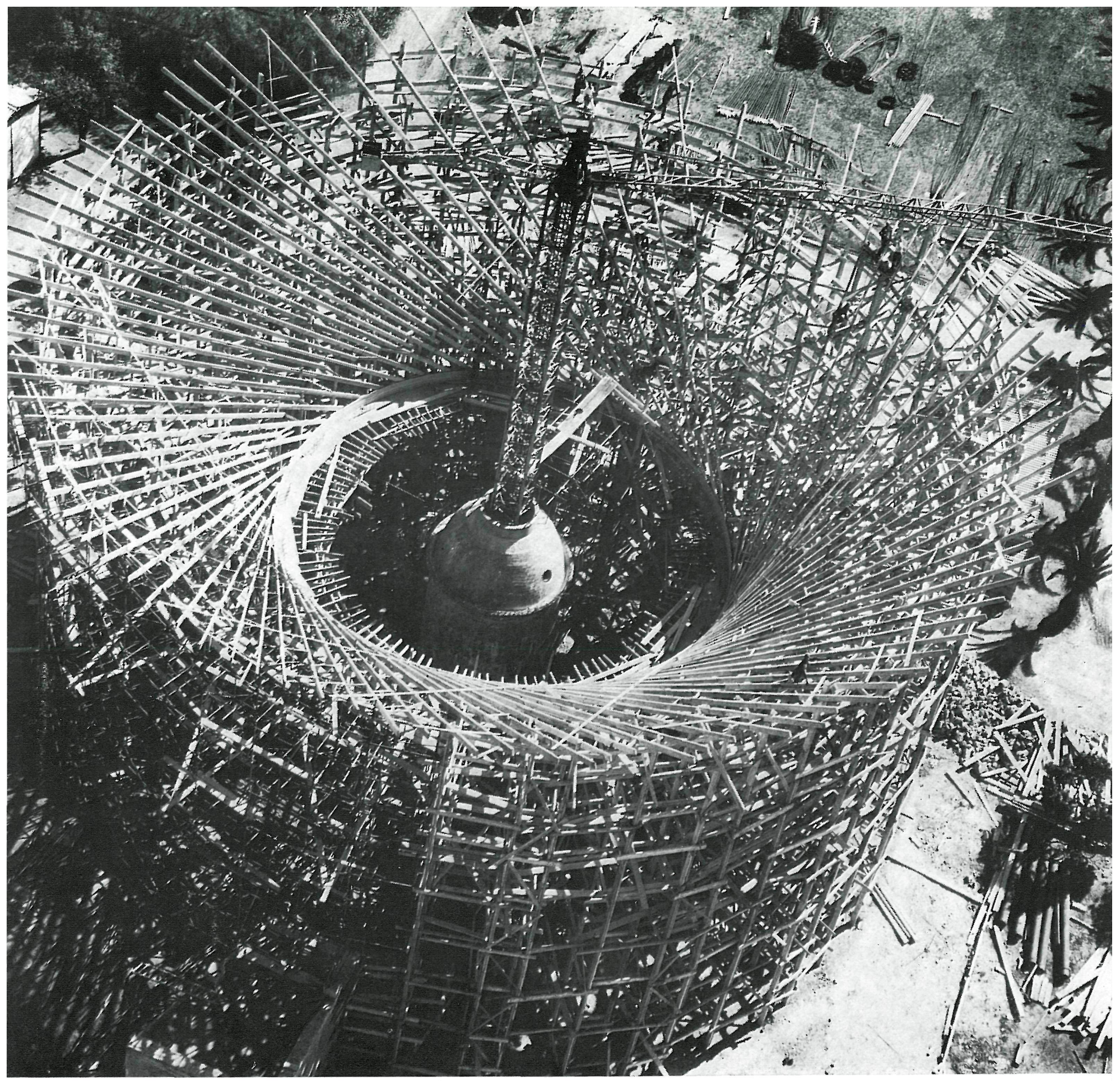

\title{
la cuba hiperbólica de Fedala
}




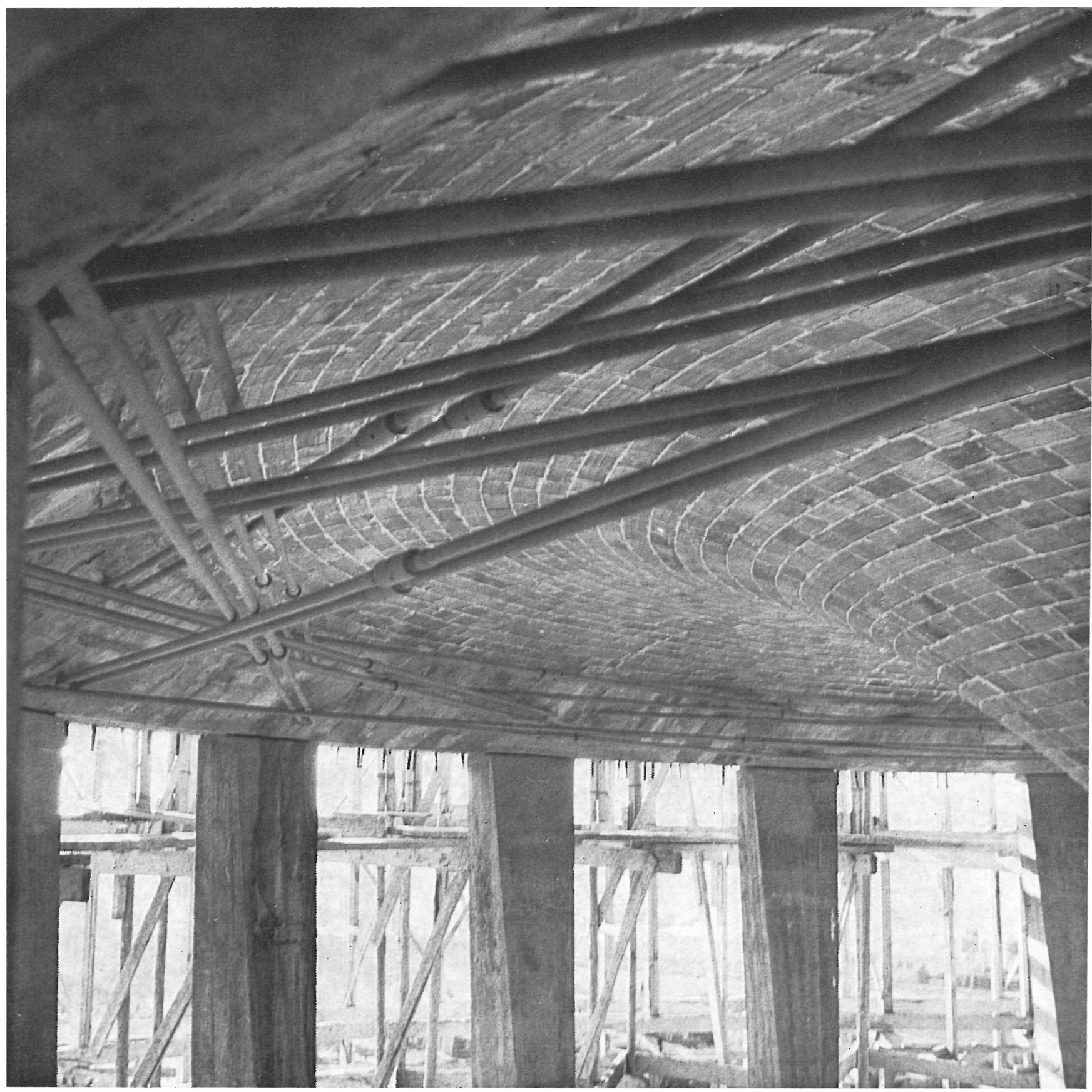

Se trata de una cuba para un depósito de $3.500 \mathrm{~m}^{3}$ de agua, montada sobre un castillete circular de soportes ya existentes de hormigón armado; y la contrata «Société Marocaine d’Entreprises Fernández» deseaba asegurar la impermeabilidad de la pared y del fondo del depósito.

Para lograrlo se adoptó una forma de hiperboloide de revolución, que permite un doble pretensado según sus dos familias de generatrices rectas.

De este modo, toda la pared queda en bicompresión y se evita el peligro de fisuración bajo la acción centrífuga de la presión hidrostática. El tesado de las armaduras se hizo por el anillo superior mediante anclajes y gatos tipo Barredo. 


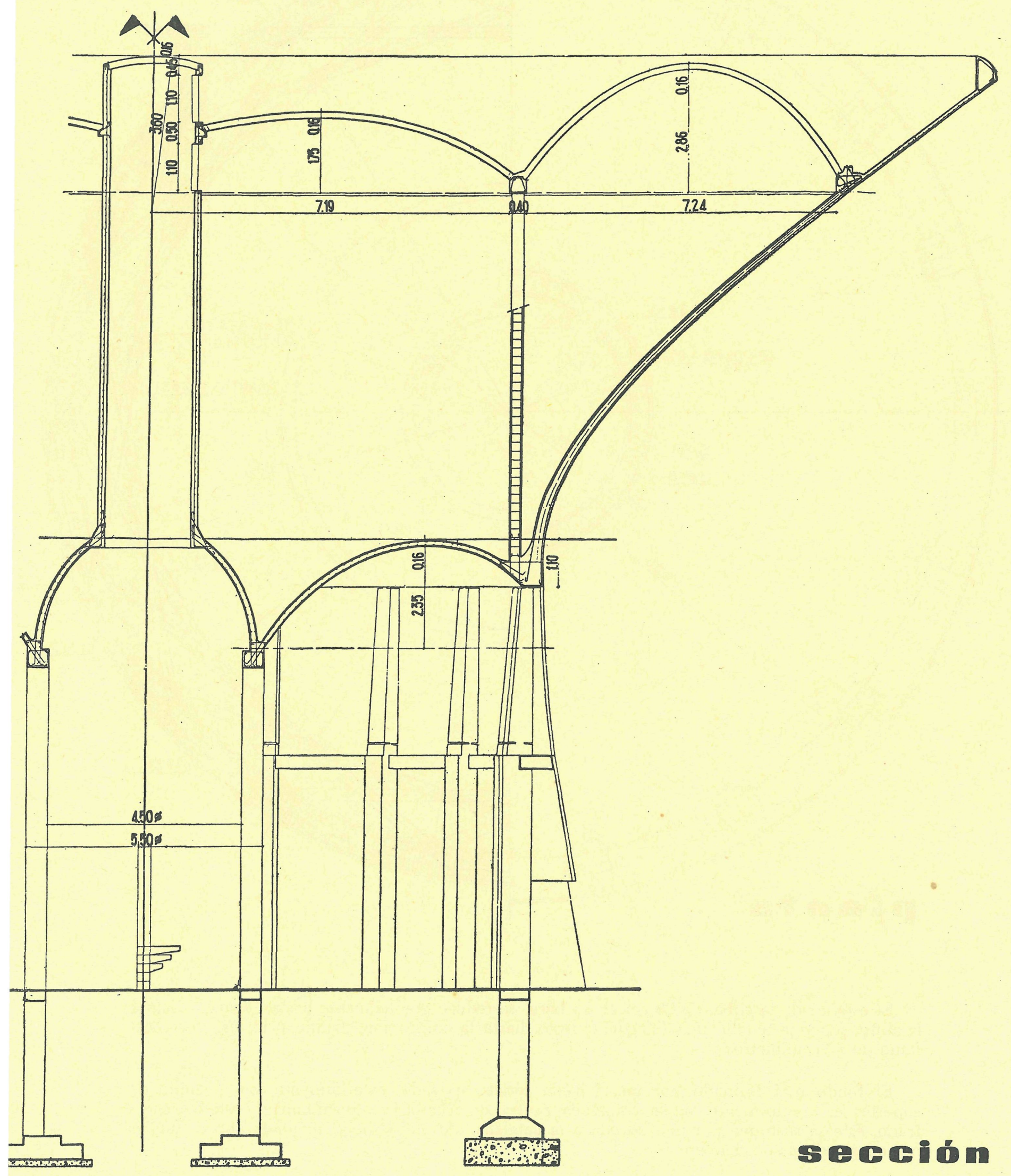




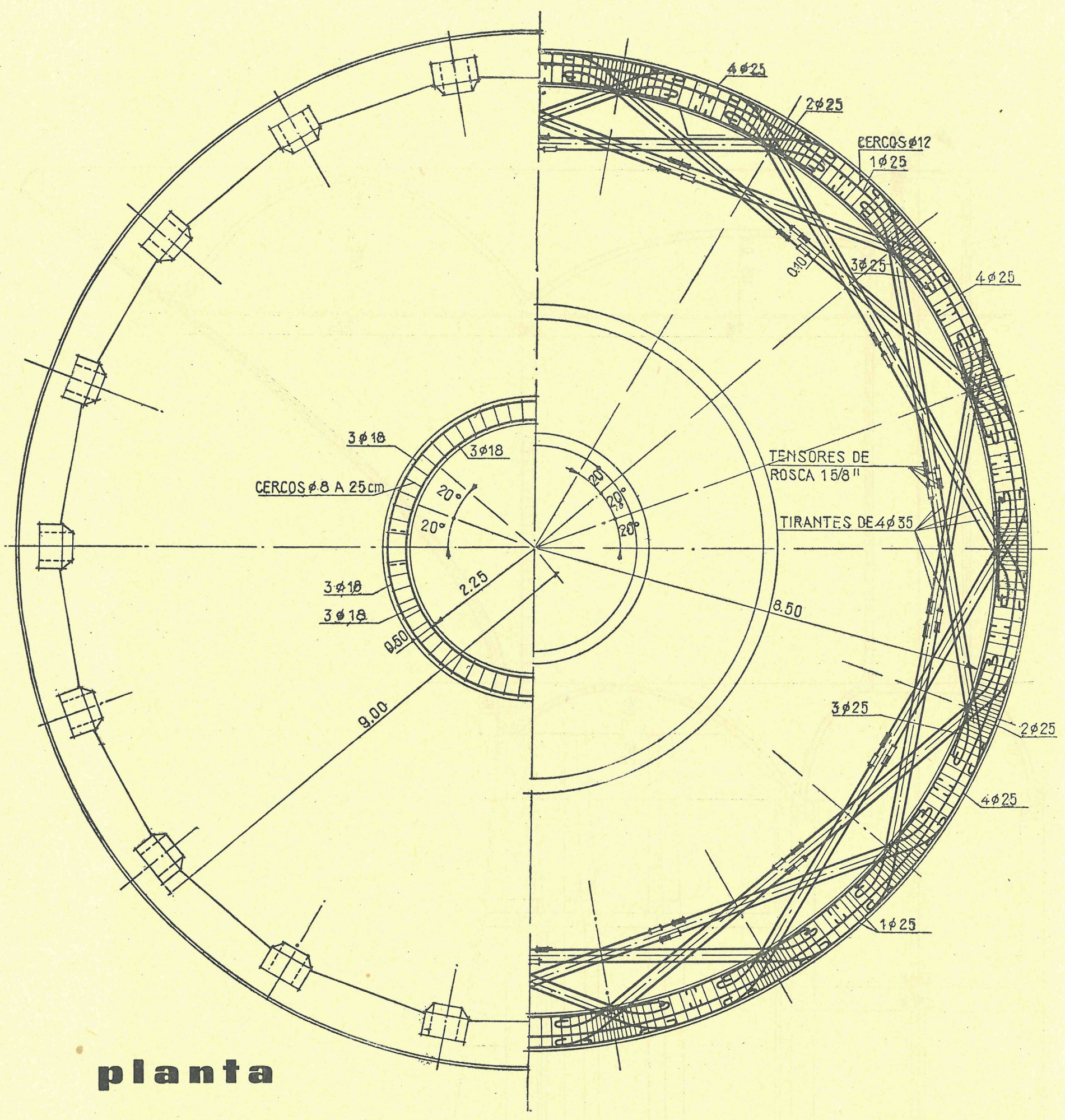

El espesor de la cuba, de $28 \mathrm{~cm}$ en su base, se reduce gradualmente hasta llegar a $17 \mathrm{~cm}$ a la altura superior de la lámina de agua; el resto, hasta la coronación, mantiene un espesor constante de 10 centímetros.

El fondo está formado por una bóveda tórica, apoyada, exteriormente, en el anillo de soportes e, interiormente, en la chimenea central de acceso. Para disminuir el coste del encofrado, éste se sustituyó por una bóveda a la catalana, de triple hoja, montada sobre simples camones radiales de madera. 
Con objeto de evitar la dilatación del anillo exterior, zuncho de la bóveda tórica en su unión con la superficie del hiperboloide, se dispuso una serie de armaduras que, por bajo del fondo, forman un polígono estrellado.

De esta manera ninguna barra tropieza con la chimenea ni con la parte central, más baja, de la bóveda tórica. Un simple tensor de rosca en cada barra permite su tesado, fácilmente regulable.

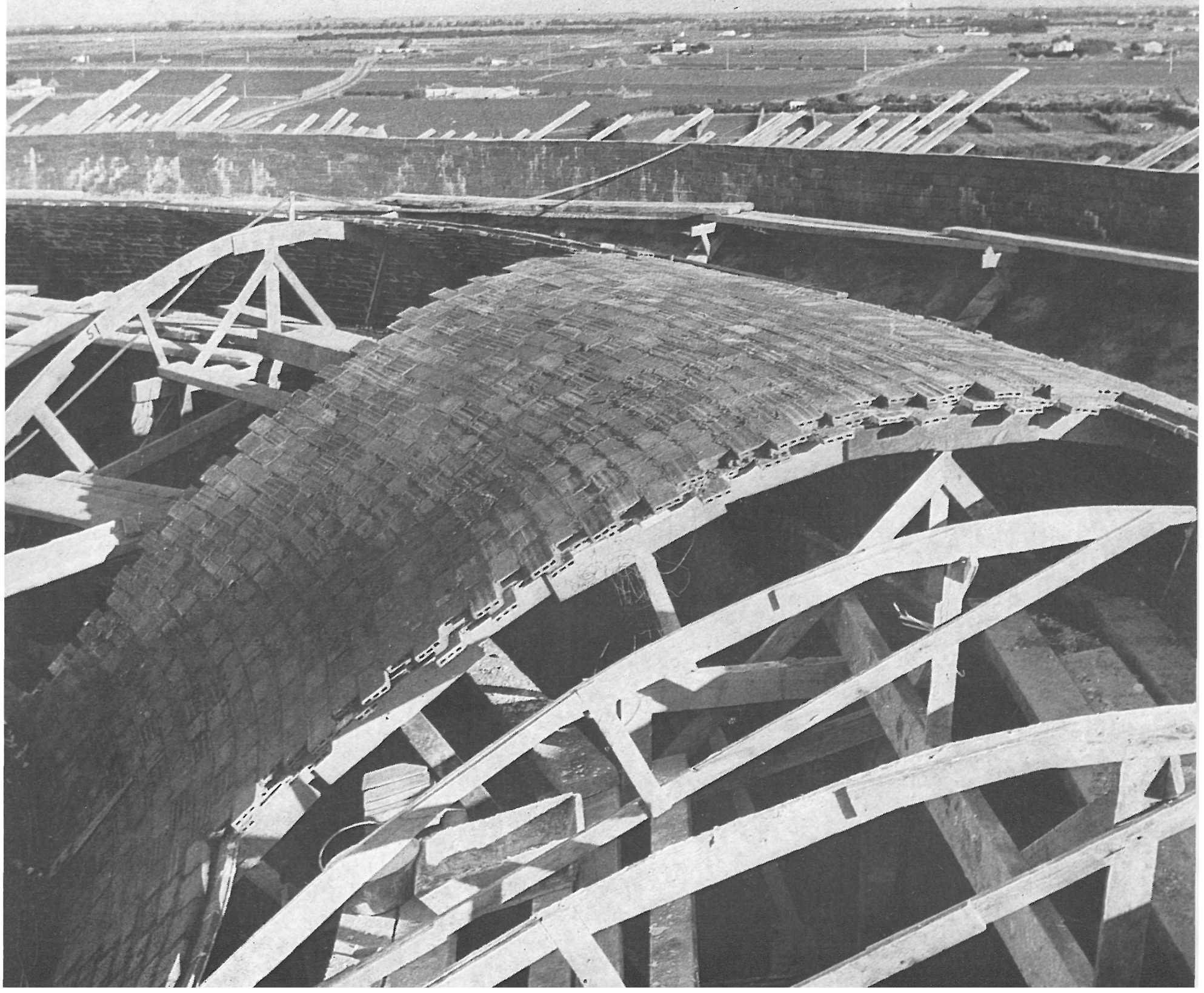




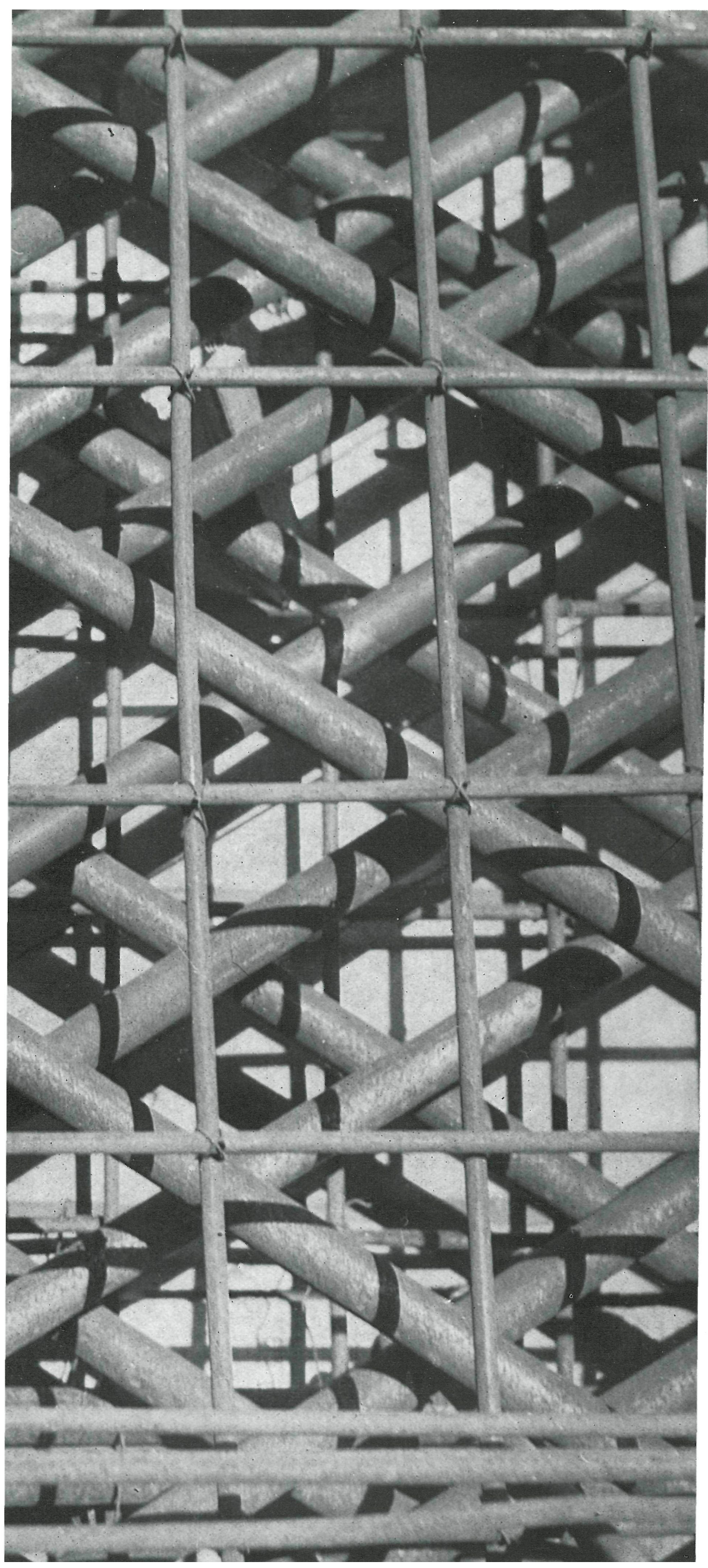

\section{armactura \\ de la pared}

La cubierta está formada por dos bóvedas a la catalana de triple hoja, de forma tórica, que se apoyan sobre tres anillos concéntricos de hormigón armado:

Uno, central, que zuncha la chimenea; otro, intermedio, apoyado en una serie de soportes que, en prolongación a los de la base, atraviesan la cuba; y el tercero, alojado en la pared exterior del vaso.

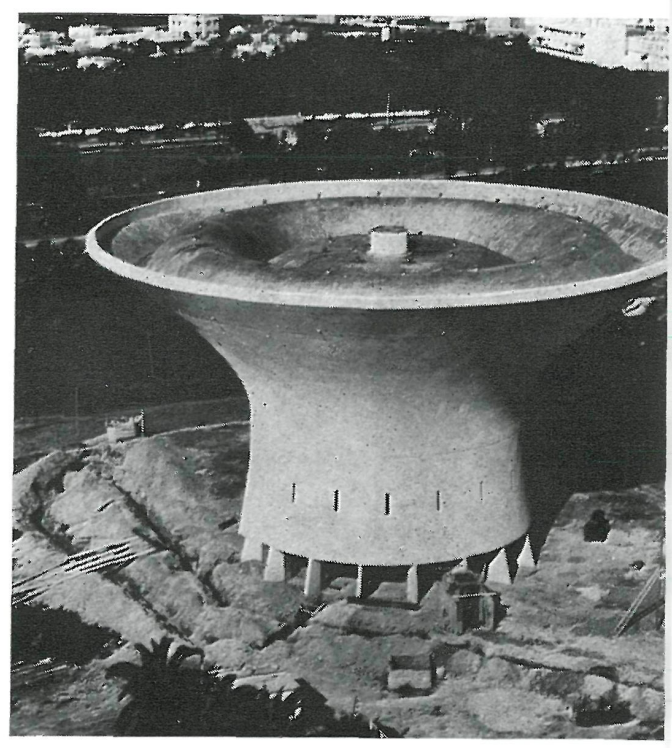

Esta construcción, cuya fotografía en color publicamos en la portada del número, es un buen ejemplo de las posibilidades formales y estructurales del hormigón pretensado. $\mathrm{Su}$ original silueta campaniforme, destacándose sobre el horizonte, constituye un punto dominante sobre la línea de cornisa y viene a ser como un símbolo del dominio de la técnica en beneficio de las condiciones de vida de un pueblo. 